\title{
Pre- And Post-Enron Learnings On Learning In M\&A Environments - A Qualitative Study In Preparation Of A Dissertation On The Influence Of Management Andragogy On Executives' Ability To Successfully Manage M\&As ${ }^{1}$
}

Jacqueline Fendt, (j@jaygroup.ch), Graduate School of Business Administration, Zurich

\begin{abstract}
In a global economy characterized by convergence and consolidation, by shareholder pressure, by the war for talent, for knowledge and for customer bondage, Merger and Acquisition transactions $(M \& A s)$ are seen as a fast, efficient and spectacular way to innovate. M\&As are therefore a frequently used strategic tool for corporate development. However, as of now, more than $75 \%$ of all M\&As fail to meet objectives and 50\% even destroy shareholder value.
\end{abstract}

$M \& A s$ often fail due to poor leadership. Therefore $M \& A s$ seem to require particular leadership and management competencies, namely the ability to lead through and manage transitions in which the manager him/herself maybe transitional (Sahl 1998). Management Andragogy, the selfdirected, incentive-driven, intercultural interdisciplinary management training that builds on executives' experience is known to develop managers' leadership and management ability.

In preparation of a dissertation on the influence of management andragogy on executives' ability to successfully manage $M \& A s$ this qualitative exploratory study investigates in the success and failure factors of M\&As, the reasons for failures and success and the management and leadership competencies favoring success, It also looks at what skills need to be developed to achieve M\&A success and explores how to develop them. The study was done before the Enron and WorldCom collapses and the Arthur Andersen failures had shaken the business community. In order to test the impact of these incidents on the investigated subject the author decided to return to the interviewees right after the WorldCom debacle to ask them the same questions again.

\section{Introduction}

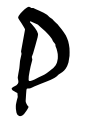

rofitability, fast growth, efficiency, agility and industry leadership are the exigent requirements that enterprises are facing in today's global economy. The attempt to satisfy these faculties and to continuously strengthen one's position in the market place has made mergers and acquisitions (M\&A) a frequently used strategic management tool for some years now. Up until the early 90 s, M\&A was one of many options of strategic partnership between companies (Gomez et al 1994), later M\&As have emerged as a key tool right through the nineties and still seem to be on the increase in some sectors of converging markets (Valentine 1999), stagnant in

\footnotetext{
${ }^{1}$ A draft of some early findings of this study, not including the post-Enron part, was presented at the Global Conference on Business and Management, July 7-9 2002 in Paris, France.
} 
others (OECD 2001), but still a highly popular entrepreneurial tool of corporate development. Counting cross-border M\&As alone, more than 40'000 deals have been registered over the past 7 years (OECD 2002) and the total value of global M\&A is estimated to have exceeded \$3.5 trillion in 2000 (Schuler/Jackson 2002). Major motives put forward (Ohmae 1990) are to quickly and sustainably increase shareholder value, to acquire one or several lacking or suboptimal strategic resources, to dominate a market or to enter into a new market/a new customer base, eg. Ecommerce; to access talent/specialist manpower (economies of skill), to purchase R\&D or even products, to obtain more control up/down the value chain, to gain economies of scale, etc. Failed M\&A transactions, on the other hand, result in considerable strategic and financial damage: they are costly, disruptive, image-damaging and emotionally wrenching experiences. And failed M\&As are by no means exceptional: research shows that a clear majority of M\&As fail (Keite 2001, Charman 1998, Watson Wyatt 2000, Grubb/Lamb 2001, Schuler/Jackson 2001). It is necessary for scholars as well as practitioners to understand the factors why some companies perform better in managing mergers and acquisitions than others. Several classes of explanations have been proposed in recent years: empirical finance and economics literature investigates in the deal-making process (Seth 1990), strategy scholars focussed on the impacts of resource, human resource and market-relatedness (Lubatkin 1987, Dierrickx/Cool 1989, Schuler/Jackson 2001) between the M\&A players and behavioralists have investigated in the culture, leadership and implications of the post-acquisition integration phase (Bowditch/Buono 1989, Kroger/Trum 2000; Schuler/Jackson 2001, Grubb/Lamb 2001). Since Enron we experience a rediscovery of the notions of values and ethics (Fendt/Baumann, 2003) right into an increase of spirituality (Walker 2002) and a strong confirmation of the necessity for human resources and cultural due diligences, i.e. early and high-level involvement of HR Leaders (Schuler/Jackson/Fendt 2003).

The processes used by companies to manage their M\&As and their implications are difficult to study empirically because of the lack of process level data typically available for a sufficiently large number of observations. Research on the process of managing mergers and acquisitions is still in the exploratory stage and is still establishing empirical regularities. The author aims to contribute to the M\&A body of knowledge in the field of organizational learning and management andragogy. A dissertation shall investigate into a possible correlation between management andragogy, leadership and management competencies in M\&A situations, i.e. in successful M\&As.

For theory development more precise data needs to be collected, in a first step through qualitative exploratory research. This paper reports on the findings from this exploratory research. The following questions interest the author in this paper:

- What are the factors that lead to success in M\&A transactions

- $\quad$ do M\&A transactions require particular competencies (leadership, managerial or entrepreneurial)

- $\quad$ if yes, can these be trained, accumulated, operationalized and how.

- $\quad$ And, finally, has Enron had an effect on executives' opinion on the M\&A success factors

It is estimated that such research on the individual and collective learning processes and their effects on the economic performance of M\&As could help executives better understand this aspect of M\&A transactions, thus increasing their chance of success and possibly help define how knowledge management and/or management learning could be improved upon for it to meet the needs of fast-changing business environments.

\section{Research Context, Purpose, Scope And Methodology}

The ultimate research purpose is to investigate the effect of management andragogy on executives' ability to successfully manage M\&A environments. This paper reports on the exploratory research aiming to produce to a more precise theory and a valid and reliable research design towards the said research purpose.

\section{Scope and population:}

Executives from upper and middle management in top-1000 organizations from german-speaking Europe (Germany, Switzerland, Austria). The sample included 82 respondents, all senior executives, from 72 distinct 
companies. 38 of the respondent companies were based in Germany, 33 in Switzerland and one in Austria. 43 or $60 \%$ of the companies have performed/been exposed to one (22\%) or more (38\%) M\&A transaction(s) after January 1995.

Methodology:

First, 11 individual depth interviews were conducted, 5 with CEOs and 6 with VPs (Marketing, Finance and Human Resources) from eleven distinct companies. A delphi-technique-like approach has been chosen in that the depth interviews of $120-200$ minutes in duration were kept fairly unstructured, with open questions letting the respondents talk about their view of M\&A situations, key success and failure factors, the competencies needed during different phases of corporate development, etc. as well their subjective preparedness for the tasks and their ideas on how to possibly prepare for them better in the future. Their comments were summarized in questionnaire form and, in a second round, verified, completed and weighted by the same respondents, resulting the following items:

\section{M\&A experience:}

- $\quad$ Likelihood that M\&As continue to be a major strategic tool for corporate development

- $\quad$ Success/Failure of own M\&A operation

- $\quad$ Subjectivity of performance measurement

- $\quad$ Metrics used to measure M\&A success

- Reasons for M\&A low impact or failure

- $\quad$ Reasons for M\&A success

- $\quad$ Management and Leadership Competencies leading to M\&A Success

- $\quad$ Skills to be developed in preparation for M\&As

- $\quad$ Perceived Skills Need in various M\&A Phases

- How to Prepare for M\&As

A telephone survey with a semi-structured questionnaire was then conducted with a larger circle of respondents and completed by 82 executives from the population, including the first eleven senior executives. The resulting data was analyzed and first qualitative interpretations made.

Then, Enron and WorldCom collapsed. In order to test the impact of these incidents on the investigated subject the author decided to return to the interviewees right after the WorldCom debacle to ask them to reread their statements and comment if, post-Enron, so to speak; their perception of and their opinion on on any of the items has changed. Since the author had earlier participated in a study on the impact of the Enron incident on executives' perception of leadership effectiveness, finding that $78 \%$ of all executives stating that Enron had changed their way of thinking about leadership effectiveness (Fendt/Baumann, 2003), some interesting findings could be expected.

\section{Findings}

M\&A experience:

Most respondents $(53,66 \%)$ had one or several M\&A experiences after January 1995. 39 (47\%) actively participated in M\&A deal planning and execution, whereas the others were oriented after the deal.

Likelihood that M\&As continue to be a major strategic tool for corporate development:

Most respondents, $78 \%$ of those who had M\&A experience and $62 \%$ of those who had not, predicted that M\&A and other strategic alliances will increase in the future. Respondents see this activity as essential to maintaining a strong market position. 
Success/Failure of own M\&A operation:

$39 \%$ of respondents that had M\&A experience claimed that their M\&A achieved or surpassed financial objectives as measured by share value, return on investment and postcombination profitability whereas $16 \%$ estimated their M\&A to have clearly destroyed value. 35\% said that the M\&A had none or minimal economic impact, or none yet. These were counted amongst the unsuccessful M\&As. All but two of the successful M\&As had performed two (or more) M\&As.

\section{Subjectivity of performance measurement:}

Much as was found in the Watson Wyatt study (2000), these executives subjectively perceive their own M\&A experience as more successful than the overall success rate of deals. Most respondents felt that whilst the figures did not yet show it, success was under way and would eventually come, but that integration activities were taking longer than anticipated and that it was too early to truly measure the success or failure of the M\&A. This aspect whether companies and/or their executives that are more critical of their performance are more likely to learn their lessons and perform better in future M\&As (Grubb, Lamb 2001) is probably worthy of exploration. Since there is a proven improved success rate among companies performing their second or more M\&A, experience seems to make a difference and therefore the aspect of learning from experience seems to be not without relevance.

\section{Metrics used to measure M\&A success:}

More than half (58\%) of the respondents did not have a clear and consistent M\&A evaluation process in place. Respondents were asked to state the metrics they use to measure success in M\&A transactions. The criteria mentioned varied widely just as did the time frame over which success was to be measured. The use of multiple criteria was stated to be decisive. No single metric dominated the responses (Figure 1).

Figure 1: Metrics Used To Measure M\&A Success

\begin{tabular}{|l|c|}
\hline Return on total capital invested (relative to WACC) & $32 \%$ \\
\hline Accounting Profits: ROI, ROE, ROA, ROS & $31 \%$ \\
\hline Free Cash flow per share & $31 \%$ \\
\hline Operating Cash flow & $26 \%$ \\
\hline Synergies & $26 \%$ \\
\hline Market share growth & $25 \%$ \\
\hline Economies of scale/cost savings & $20 \%$ \\
\hline Change in shareholder values & $16 \%$ \\
\hline Share price at 3 years after announcement & $16 \%$ \\
\hline Key talent retention & $11 \%$ \\
\hline Share Price at 1 year after announcement & $8 \%$ \\
\hline Share Price around deal announcement & $4 \%$ \\
\hline
\end{tabular}

Considering that key talent retention and human factors were rated high throughout the study, it was surprising to find a single qualitative criterium and with quite a low result. Other non-economic, sustainable criteria such as innovation capacity, staff fluctuation, image, job satisfaction, etc. were only mentioned sporadically.

Reasons for $M \& A$ low impact or failure stated by $M \& A$-experienced respondents were typically:

- $\quad$ unrealistic expectations, poor or no due diligence, valuation too high

- $\quad$ questionable driving forces for the M\&A, personal reasons, "hybris hypothesis" (Roll 1986); conflict of interest between board and management (value capturing vs. value creation) 
- $\quad$ inability to agree on a common greater vision, inability to communicate such a vision; dismissal of key executives, loss of key talent, loss of experience and know how, loss of trust

- $\quad$ too many consultants

- $\quad$ distraction of executives from core business

- $\quad$ neglect customer attention, loss of key customers

- $\quad$ incompatibility, ignorance of culture gap, underestimated cultural differences, none or not enough formal transition and integration planning and management, especially degree/level of integration not defined and not communicated

- $\quad$ learnings, experience, knowledge, progress not formalized, not documented/codified

- $\quad$ transition resources, costs and finance drain underestimated

- decisionmaking and implementation too slow, everything takes too much time, momentum is lost, confusion prevails

- $\quad$ external reasons (e.g. 9/11, stock market crash, etc)

This result concurs strongly with findings from Charman (1998) with the difference that here an even larger importance is given to culture and human factors, expecially the questions of trust, learning and communication, where the strongest deficits are identified.

Factors for M\&A low impact or failure stated by $M \& A$-inexperienced respondents were typically:

- $\quad$ Incompetent top management, excessive compensation packages

- $\quad$ wrong driving forces for the M\&A decision, served only personal goals of CEO

- $\quad$ valuation, i.e. purchasing price too high

- $\quad$ cultures don't fit, no sense of unity between the two players

- $\quad$ top executive defection

- $\quad$ unrealistic synergy/scale economy expectations

- $\quad$ transition costs underestimated

M\&A-inexperienced executives anticipate the stumbling blocks in M\&A transactions almost exclusively in the financial and strategy areas. The only soft factor mentioned is culture fit.

When asked to explain their company's $M \& A$ success, respondents from successful M\&As stated primarily:

- $\quad$ good match, genuine value drivers (as opposed to "political" or "power" reasons); complementarity

- $\quad$ transition management skills, adaptability

- $\quad$ experience from previous M\&As, i.e. formal (knowledge documented) and informal (experience accumulated) learning from such previous experiences

- $\quad$ strong, visible, credible leadership with executives from both companies, commitment, a climate of trust

- $\quad$ solid and professional diligence and planning work during conception and transaction phases

- $\quad$ clear-cut shared goals and objectives, clearly and truthfully communicated

- $\quad$ regular and extensive communication to shareholders, customers, employees and other stake holders

- $\quad$ specific, experienced M\&A transition team help to implement fast and constantly report on progress made

- $\quad$ visibly and commonly acknowledge and solidify each intermediary step, codify learnings, knowledge

- $\quad$ common management training with executive teams from both firms

Management and Leadership Competencies:

The successful companies in the survey attributed their success to the following management and leadership competencies:

- $\quad$ win-win: align expectations between the merging players early and clearly

- $\quad$ focus: limited oneself to a few, simple clear-cut value drivers and focus on these and only these 
- $\quad$ clarity: made the tough decisions early, implement them right away and communicate frankly and clearly

- $\quad$ early planning: start the planning of transition and integration activities earlier

- $\quad$ accumulate experience, document knowledge and transfer actively

- $\quad$ recognize the strengths in the other and combine it

- $\quad$ move swiftly but plan with realistic time scales allowing for enough time

- $\quad$ people make the difference: recognize human factors and involve HR early

- $\quad$ use consultants but commit personally, don't lose touch, keep control

Skills that should be developed in preparation for M\&As:

M\&A-experienced respondents' most frequently mentioned skills to be developed to prepare executives for M\&A situations are:

- vision skills: to learn to see and communicate a long-term "greater picture"

- personal commitment and integrity: to put the task before one's own immediate personal ambition and, possibly, fear

- $\quad$ corporate commitment: to develop and communicate a joint intent and ensure stakeholder support

- $\quad$ cultural sensitivity: to familiarize with different corporate and national cultures, possibly languages

- $\quad$ flexibility, an open mind: exposure to a multitude of other structures, processes, disciplines, industries, etc.

- emotional intelligence/social competency: to accept to work with executives from the "other" company

- management and analytical skills: to be able to "read" organizations quickly and identify their strategic, financial and human assets and liabilities and propose win-win solutions

- learning ability: to analyze situations consciously and effectively and draw learnings from them and to explicitely document/codify this acquired knowledge

- focus: despite hectic times to concentrate on some few essential business drivers and not be distracted

- $\quad$ planning skills: methods and techniques of project planning and management

- $\quad$ transition skills: to give stability when everything moves

M\&A-inexperienced respondents' most frequently mentioned skills to be developed to prepare executives for M\&A situations are:

- personal commitment and integrity: to put the task before one's own immediate personal ambition and, possibly, fear

- $\quad$ methods and techniques: due diligence, deal structure and strategy skills

- $\quad$ flexibility, an open mind: exposure to a multitude of other structures, processes, disciplines, industries, etc.

- $\quad$ analytical skills: to be able to "read" organizations quickly and identify their assets and liabilities

- learning ability: to analyze situations consciously and effectively and draw learnings from them

Skills Need in various M\&A Phases:

In oder to determine their perception of the skills needed in the different steps (Schmidt 1999) or phases (Steinöcker1998, Jansen 1999, Fendt 2001) of the M\&A process, a diagram was shown and respondents were asked to compose their own team for a hypothetical forthcoming M\&A transaction, for each of the four phases in the diagram (Figure 2). 
Figure 2: Phases In Mergers And Acquisitions

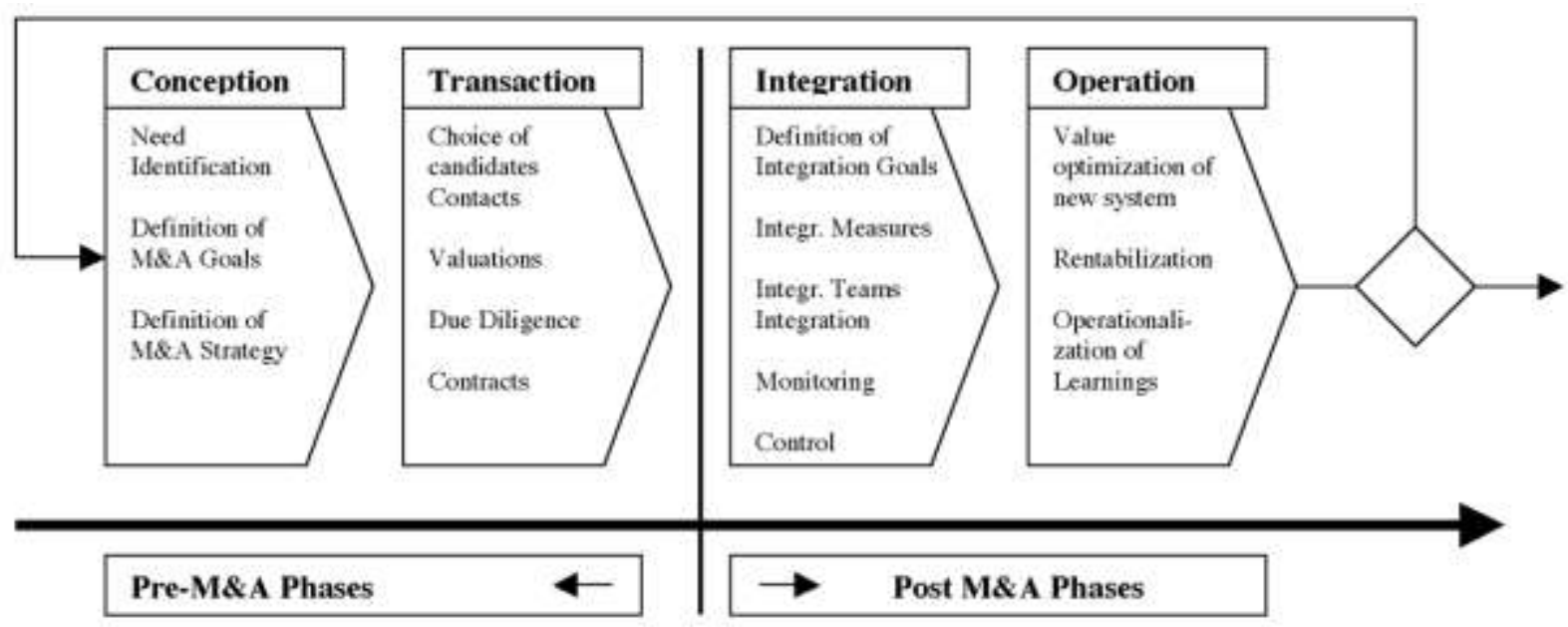

The results are summarized in Figure 4 for the respondents with M\&A experience and Figure 3 for respondents without M\&A experience. Most striking is the difference in importance the two groups attribute to the presence of the human resources (HR) and the communications (PR) executives in the early M\&A phases: Only $35 \%$ of M\&A-inexperienced respondents saw a necessity to involve HR in the conception phase and even less, namely $28 \%$ in the transaction phase, whereas $72 \%$ of the M\&A-experienced respondents would involve HR in the conception phase and $82 \%$ in the transaction phase. The corresponding figures for PR are $33 \%$ and $45 \%$ vs. $63 \%$ and $65 \%$.

Figure 3: M\&A-Inexperienced Respondents' Choice Of M\&A Team Per Phase

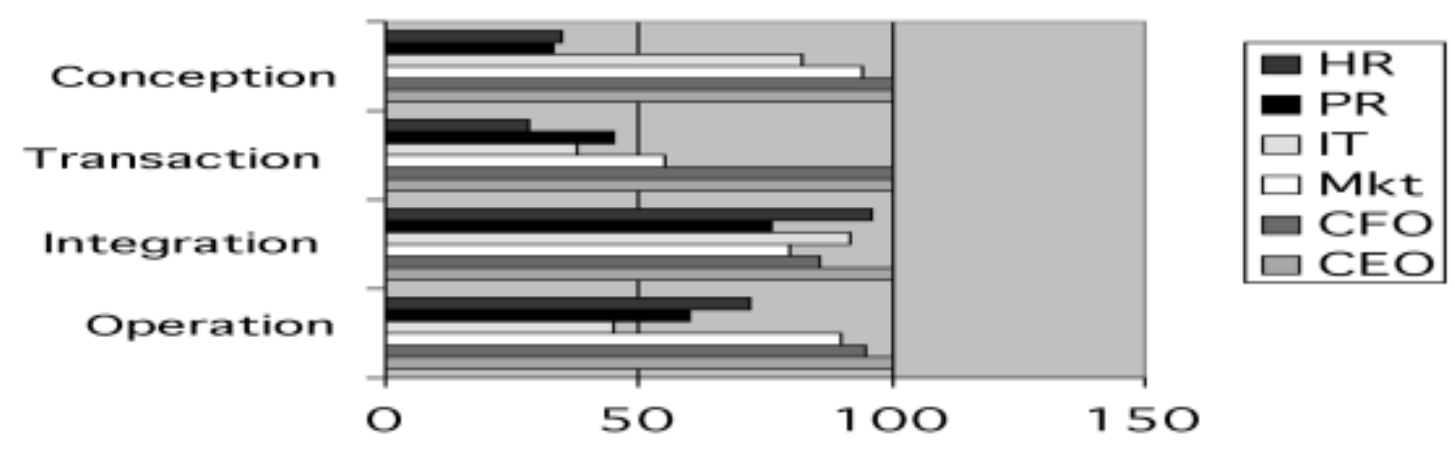


Figure 4: M\&A-Experienced Respondents' Choice Of M\&A Team Per Phase

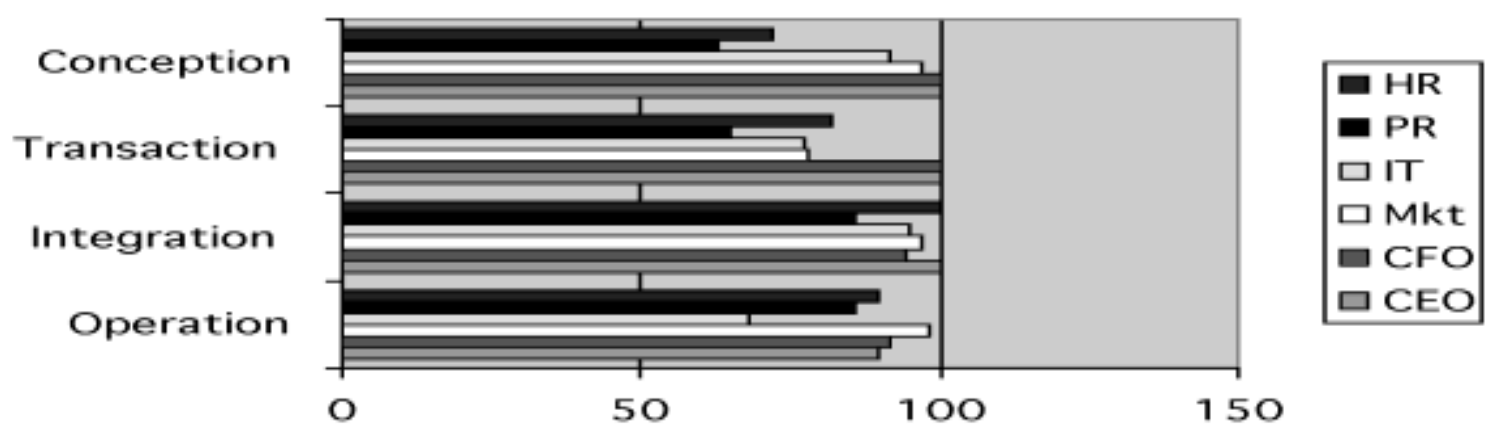

Preparing for M\&As:

Preparation for M\&As is considered important by a large majority of respondents (67\%) although ideas on content and form of such preparation vary considerably. Especially very experienced respondents claim to recognize recurring patterns and stress on the importance of experience documentation and training, whereas inexperienced respondents tend to doubt the significance of the capability-building effect, stating that: "every deal is different".

The following are the most frequent proposals made with respect to how to prepare for M\&As:

- $\quad$ the best preparation for M\&A is to do/experience one/several M\&As! Since this cannot be always provided and to do an M\&A just for practice would probably be unreasonable, the next best preparation is a form of training that comes as close to the real thing as possible:

- $\quad$ participation in real projects with multidisciplinary, multicompany and international scope

- $\quad$ international exposure

- $\quad$ intercultural exposure

- $\quad$ work in transition environments, in ephemeral systems, in temporality; change projects, learn to adapt

- $\quad$ acquire a solid box of management tools

- $\quad$ keep abreast of competition and the industry

- $\quad$ build a strong network of acquaintances and friends within the organization and beyond

\section{Post-Enron Verifications}

Executives (who of course had, since their first depth interview, not only experienced the Enron, AA and WorldCom et al crises but also increased their own personal M\&A experiences - and whose possible reconsiderations are therefore also a result of this newly acquired or enhanced personal experience) have confirmed to a large extent their prior statements. Modifications, however, appear in their prioritization and weighting of certain items. Also, some completely new points were mentioned which had not, or not so explicitely, been mentioned in the first round.

Overall it can be said that the post-Enron verification round has yielded an even more radical accentuation of the learnings that were found between M\&A-experienced and -inexperienced executives: items that had become more weight through M\&A experience, did so here even more, such as: 
- $\quad$ the early involvement of HR leaders, as key players as early as the very beginning of the conception and due diligence phase:

- $\quad$ the conscious consideration of culture as a key element to success, equal to financial and technological issues, and therefore worthy of analysis, strategic reflection, definition (complementarity) and assessment; another deficit that came up in the culture context was insufficient language skills. In global mergers executives tend to "declare English the corporate language" and assume that by having done this, it is so. But even though most executives have a fairly decent command of the lingua franca of the occidental management world, this does not make them capable of understanding the finesse or deeper sense of a crucial remark in a conversation or the often specialized language in a formal strategic, financial, technological and/or legal, etc. negotiation;

- the intent to keep a maximum of existing resources, including the merging partner's top management team, rather than dismiss it or allow it to defect;

- $\quad$ the attention- whilst working intensively with consultants, especially in complex and specialized areas such as technology, legal, etc. - to be given to keeping the reigns well in hand when working with consultants and to be at all times a visible, active and decision-making principal;

- the steep learning curve of M\&A, the firm conviction that, whilst the experience of the "real thing" is priceless, it is also costly and therefore M\&As must and can be up to a certain extent practiced in "dry runs". Even more radically than before these executives confirmed that they themselves and especially many colleagues were not really prepared for such a complex and demanding managerial situation at all and that many executives (here the executives spoke as a rule of "some colleagues" and only rarely of $\mathrm{him} /$ herself but it might be assumed that, whilst not always specifying it, self was meant as well) were not only not prepared for M\&A but that many (often having been promoted to management from engineering or production or R\&D, etc and insufficiently trained) generally lacked a solid managerial toolbox and therefore have/had to rely much too soon on collaborators (especially in finance) and/or consultants.

One new item not explicitely mentioned prior was that executives were "simply under too much pressure" by stockholders, analysts, journalists, etc., who forced them to set too ambitious and unrealistic goals.

\section{Implications And Conclusion}

\section{On Culture}

Almost all M\&A-experienced respondents admit to having first totally underestimated the culture and human elements of M\&A integration - and more so post-Enron. Much attention in the conception and transaction phases was given to strategic and organizational/structural fit. There was, so they explained, "no time" to treat human, diversity and culture questions and they were, if considered at all, seen as part of the implementation phase or the company considered itself sufficiently international and "multicultural" to expect these issues to work out "automatically". A simple diagram depicting the company as a system composed of the three elements strategystructure-culture shows that a focus on structure and strategy alone is too mechanistic an approach when integrating two independent and often very different corporate cultures (Pümpin et al 1985, Schmidt, 1999: Figure 5).

Despite the repeated mention of the importance of culture, no correlation could be found between cultural fit and success. On the contrary: many respondents firmly insist that cultural difference and complementarity even contributed to success.

Propositions :

- $\quad$ The earlier the attention to cultural issues, the greater the economic performance of the target M\&A, and

- The higher the complementarity of the two cultures, the greater the economic performance of the target $M \& A$ 


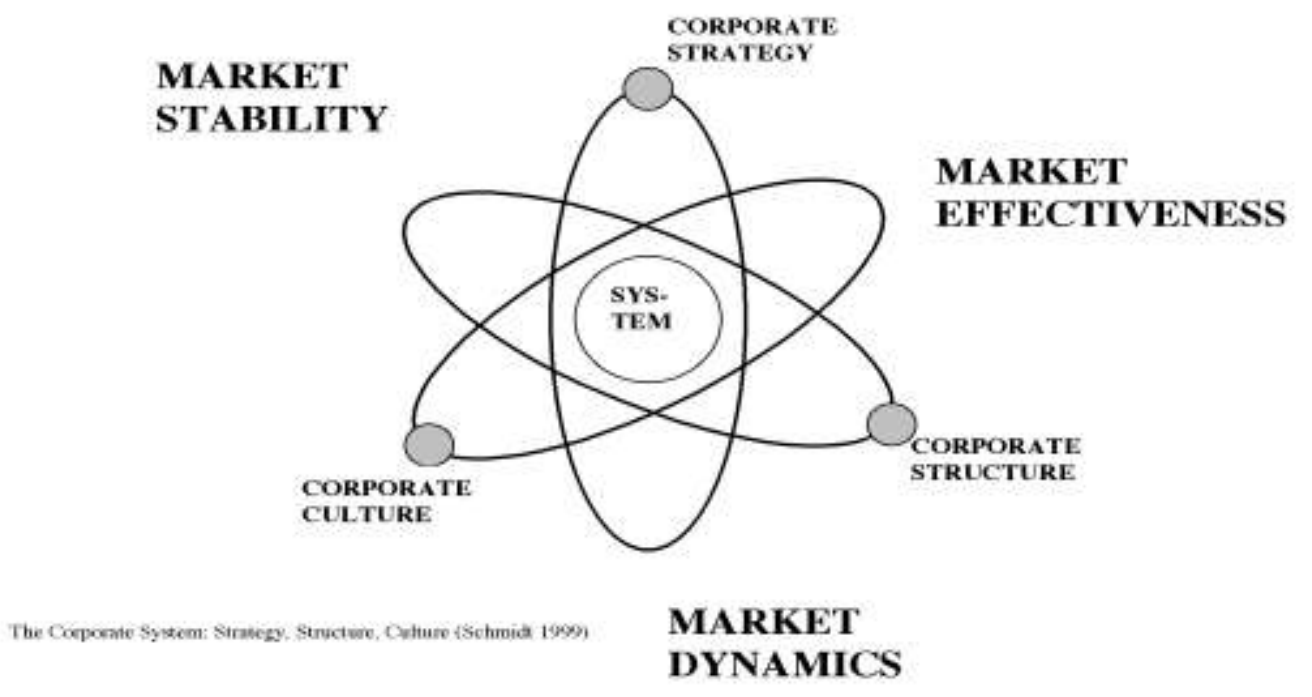

\section{On Integration}

To determine the degree of integration intended is seen as very important for success. Two types of assessment are proposed: the degree of strategic interdependence among the two firms and the need for organizational autonomy necessary to saveguard and further develop each company's particular competencies: preservation/coexistence, symbiosis, absorption/assimilation or transformation/novation (Krusche 2000). In first mergers strategic and structural arguments are seen to determine the choice and culture seems to follow. Accordingly, executives tend to choose a preservation strategy in their first M\&A but increase the degree of integration as their experience with transitions increases which is positive since research shows a positive correlation between degree of integration and M\&A success (Harbir/Zollo 1999).

\section{Propositions:}

- $\quad$ The greater executives' transition skills, the higher the degree of integration in the merged company and - $\quad$ The stronger the integration of the two firms, the higher the economic performance of the merged company

\section{On Top Management Dismissal vs. Retention vs Defection}

Another strong point put forward by most executives from successful M\&As concerns the handling of existing resources within the two companies, primarily the human and social capital, particularly the merged or acquired partner's top management team. The degree to which post-M\&A turnover of human resources is actively pursued in an attempt to implement changes quickly and obtain the targeted performance improvements has been researched in a number of empirical studies (Cannella/Hambrick 1993, Krishnan et al 1997), all stating that it was better for performance to work with existing resources, especially top management. This study also confirms these findings, namely that managerial turnover is harmful to M\&A performance and the impact even increases with the number of senior executives dismissed and/or defecting. Respondents clearly stated that continuity with existing management teams was positive and that complementarity between the two top management teams strongly influenced positive performance.

Proposition:

- The fewer top management replacements during the transition the higher the economic performance of the merged company 


\section{On Consultants}

M\&A are complex processes where stakes are high and stakeholders present. They also require highly specialized skills in all process phases. One inevitably has to deal with numerous stakeholders and work with a variety of consultants from various fields (Figure 6, Actors in the M\&A Process):

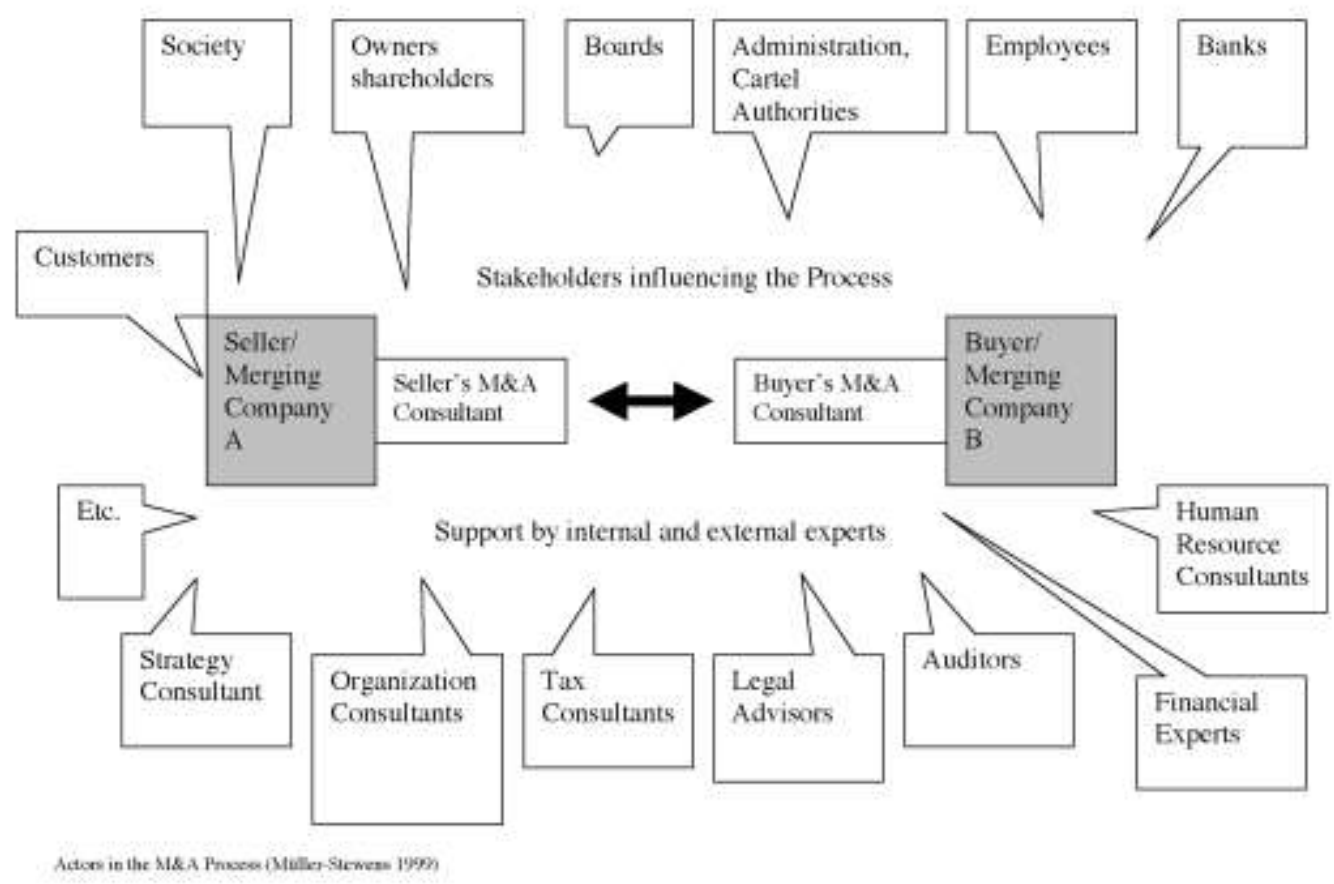

Respondents felt this to be a heavy burden, especially in spectacular deals where negotiations and conflict management etc. are virtually done in front of live news cameras. In the Post-Enron Verifications some admitted to them and/or some of their colleagues being insufficiently prepared for the assignment, lacking in management tools and methodologies and, in multilingual M\&As, not feeling completely versed and adept in the foreign language (English), and tended therefore to rely on consultants more, i.e delegate more power to consultants or also not give consultants precise enough assignments and/or finally not question their proposals enough. Often consultants tend to develop their own dynamic, be it in an attempt to enlarge their mandate, or because they are simply left the battlefield for various reasons (some mentioned above) and become very dominant. One executive (CTO) told of a situation when in a transaction phase of a buying and a selling airline he was spontaneously called in to what turned out to be a rather crucial meeting on some key strategic and financial issues with eight consultants, advisors etc from one company and as many from the other and not a single representative from either principal! Whilst this may be exceptional, most executives occasionally felt uncomfortable with the number of consultants to deal with in such situations and M\&A-experienced respondents insist on the importance for executives to stay in charge and keep control and to have some skills in the complete deal flow to be able to do so.

\section{On Human Resources}

The success factors are a variety of financial, strategic and cultural factors with none prevailing. Leadership and other human factors are key and seem to be given more and more attention by executives. Still, executives still underestimate these human issues when approaching an M\&A for the first time and focus primarily on financial and strategic aspects. A formidable learning process seems to take place when performing a first M\&A transaction and 
subsequent integration, which considerably changes executives' perception of key success factors and also their behavior. They make key decisions more quickly, communicate them clearly, plan earlier and more thoroughly and involve HR much earlier. This has again been accentuated in the post-Enron verification round.

Proposition:

- $\quad$ The earlier HR is involved the M\&A team the higher the economic performance of the acquisition

On Experience in Transition

One striking finding in this study is the positive influence of experience on M\&A success. The more M\&A transactions respondents had performed the more successful they were. Some executives did not document learnings because of the ephemeral nature of the moment, feeling it not necessary because things would change again, whereas the successful executives did document learnings explicitely for the same reason, namely because of the transitionality of the moment, anticipating such situations to happen again and wanting (self and organization) to be prepared for this. In companies where executives had understood the capability-building mechanism of experience accumulation in a transitional phase and carried it beyond the tacit accumulation into explicitely documenting this knowledge for it to be available to the organization the positive impact on performance was very marked. The positive impact of knowledge documentation in transitions increases as the post-M\&A integration progresses and the organization becomes increasingly complex (confirms findings by Harbir/Zollo 1999).

Propositions:

- $\quad$ The greater the leading executives' M\&A experience, the better the economic performance of the target $M \& A$

- $\quad$ The greater the executive's ability to manage transition the higher his/her determination to document the experience and transfer the knowledge

- $\quad$ The more experience is documented and knowledge transferred the better the economic performance of future M\&As

- The more complex the organization becomes the higher the positive impact on performance of knowledge documentation and transfer

\section{On Learning}

Respondents are unanimous that the best possible preparation for M\&As is to do one or several M\&As. They estimate that the essential skills for M\&A management, namely to manage transitions, could be developed in conditions that simulate the true experience of M\&A as much as possible.

In the field of management andragogy a number of learning transfer methodologies (Figure 7; Cormier 1987, Stähli 1992, Rouiller et al 1993, Broad 1997, Mailick/ Stumpf 1998, Fendt 2001) have been developed over the past two decades that could satisfy these requirements. Especially the genetic case study (Stähli 1992), which juxtaposes management consulting and management development by enrolling executives from their working environment for short periods of time to confront them in case study form with real, actual entrepreneurial problems takes near transfer (Clark 1999) a step further. 
Figure 7: Management Development Techniques (Mailick/Stumpf 1998, completed by Fendt 2001)

\begin{tabular}{|c|c|c|c|c|}
\hline $\begin{array}{c}\text { Management } \\
\text { Development Techniques }\end{array}$ & Development Objectives & Focus of Change & $\begin{array}{l}\text { Learning } \\
\text { Domain }\end{array}$ & Behavioural Science Roots \\
\hline 1. Programmed Learning & Knowledge Acquisition & Individual & Cognitive & $\begin{array}{c}\text { Behaviorist Psychology: Learning } \\
\text { Theories/Skinner }\end{array}$ \\
\hline 2. Lectures/Discussions & Knowledge Acquisition & Individual & Cognitive & Socratic methods \\
\hline 3. Case Method & $\begin{array}{l}\text { Knowledge acquisition; } \\
\text { some Behavioral Change }\end{array}$ & Individual & Cognitive & $\begin{array}{l}\text { Cognitive Psychology; Informa- } \\
\text { tion Processing, problem Solving, } \\
\text { Decision Making }\end{array}$ \\
\hline 4. Games & Knowledge Acquisition & Individual & Cognitive & Cognitive Psychology \\
\hline $\begin{array}{l}\text { 5. Sensitivity and } \\
\text { Laboratory Training }\end{array}$ & $\begin{array}{l}\text { Attitudinal and behavioral } \\
\text { change }\end{array}$ & $\begin{array}{l}\text { Individual and/or } \\
\text { group }\end{array}$ & $\begin{array}{l}\text { Cognitive } \\
\text { and } \\
\text { affective }\end{array}$ & $\begin{array}{l}\text { Social Psychology: Attitudinal } \\
\text { research, Social Change Theory } \\
\text { /Lewin; Behaviorism/Skinner; } \\
\text { Pragmatism Dewey }\end{array}$ \\
\hline 6. Behavioural Simulations & $\begin{array}{l}\text { Knowledge Acquisition, } \\
\text { Behavioral Change, } \\
\text { Attitudinal Change }\end{array}$ & Group & $\begin{array}{l}\text { Cognitive } \\
\text { and } \\
\text { affective }\end{array}$ & $\begin{array}{c}\text { Pragmatism/Dewey; } \\
\text { Behaviorism/Skinner; Social } \\
\text { Psychology: Group Dynamics, } \\
\text { Social Change Model; Atttitude } \\
\text { Research }\end{array}$ \\
\hline 7. Action Learning & $\begin{array}{l}\text { Knowledge Acquisition; } \\
\text { behavioral change, } \\
\text { attitudinal change }\end{array}$ & Group & $\begin{array}{l}\text { Cognitive } \\
\text { and } \\
\text { affective }\end{array}$ & $\begin{array}{c}\text { Pragmatism/ Dewey; } \\
\text { Behaviorism/Skinner; Social } \\
\text { Psychology: Group Dynamics, } \\
\text { Social change model, Attitude } \\
\text { research }\end{array}$ \\
\hline $\begin{array}{l}\text { 8. Genetic case study; } \\
\text { living case }\end{array}$ & $\begin{array}{l}\text { Knowledge acquisition; } \\
\text { behavioral change; } \\
\text { attitudinal change; } \\
\text { responsibilization }\end{array}$ & $\begin{array}{l}\text { Group and } \\
\text { individual }\end{array}$ & $\begin{array}{l}\text { Cognitive } \\
\text { and } \\
\text { affective }\end{array}$ & $\begin{array}{c}\text { Pragmatism/Dewey; } \\
\text { Behaviorism/Skinner; } \\
\text { Social Psychology: Group } \\
\text { Dynamics, social change model, } \\
\text { Attitude research }\end{array}$ \\
\hline
\end{tabular}

Mergers and Acquisitions can, like any other challenging entrepreneurial task, be learned and effectively managed in a value-creating way. Management Andragogy, especially in its most developed form of the Genetic Case study (Stähli, 1992 and 1999; Fendt 2002) which trains executives' responsibilization, can be an effective way to prepare executives for that culturally, technically and entrepreneurially demanding managerial task that is an M\&A. The proposed dissertation theory:
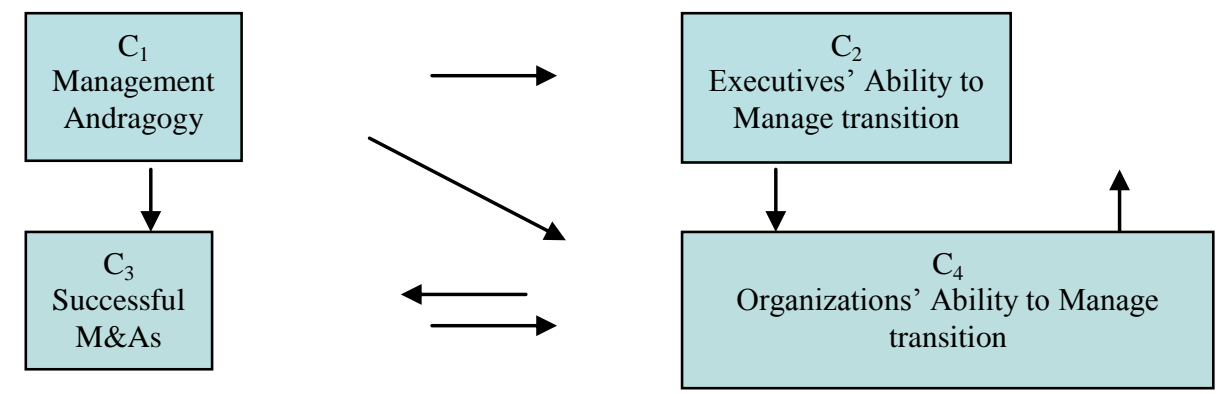
Correlating $\mathrm{C}_{1}$ : management andragogy, $\mathrm{C}_{2}$ : executives' ability to manage transition and $\mathrm{C}_{3}$ successful $\mathrm{M} \& \mathrm{As}$, the propositions being:

$\mathrm{P}_{1}: \quad$ Executives can improve their ability to manage transition through management andragogy

$\mathrm{P}_{2}$ : $\quad$ Organizations can improve their ability to manage transition through management andragogy

$\mathrm{P}_{3}$ : The greater executives'ability to manage transition, the better the economic performance of their target $\mathrm{M} \& \mathrm{~A}$

$\mathrm{P}_{3}$ : The greater organizations'ability to manage transition, the better the economic performance of their target M\&A

seems to have gained in plausibility with this qualitative study and shall be operationalized and then researched empirically. We will pursue this field in the hope to come up with some indications helping to identify the advantages of bridging and integrating different theoretical and practical perspectives offering executives a clearly defined and relevant account of the conditions and competencies under which competitive advantage can be gained or destroyed in M\&A processes and similar transition environments.

\section{Further Studies}

Any of the above propositions on culture, integration, top management retention or HR upon M\&A performance should give fascinating grounds for further research. An additional research path to pursue might be the correlation between speed of implementation and success clearly contradicts the above-mentioned executives' expectations that "...well, things take longer but success will soon come". In fact, this qualitative data seems to indicate with great clarity that the longer the transition period of an M\&A project the less likely it will succeed. This subject, success rate of M\&As on the implementation time scale, could well be gratifying to explore further.

\section{References}

1. Bowditch, J. L., Buono, A.F. (1989) The Human Side of Mergers and Acquisitions, San Francisco 1989

2. Brookfield, Stephen D. (1986), Understanding and Facilitating Adult Learning, San Francisco Jossey Bass

3. Broad, M. (1997), Transferring learning to the workplace, Alexandria, American Society for Training and Development, 1997

4. Brown, J.S. and Duguid, P. (2000), The Social Life of Information, Harvard Business School Press

5. Cannella, A.A. Jr., Hambrick, D. C. (1993), Effects of Executive Departures on the Performance of Acquired Firms, Strategic Management Journal 14 137-152, 1993

6. Charman (1998) A.T. Kearney Study conducted in 1998 and reported in Haebeck, M.H., Kroger, F. and Trum, M.R. (2000) After the Mergers: Seven Rules for Successful Post-Merger Integration (Prentice Hall/FT: New York/London);

7. Charman, A. (1999), Global Mergers and Acquisitions, Alexandria, VA: Society for Human Resource Management

8. Clark, R. (1999), Training Complex Cognitive Skills, http://www.clarktraining.com/research/merrienboer.html

9. Cormier, S., Hagman, J. (1987), Transfer of learning, San Diego, Academic Press, Inc.

10. Dewey, J. (1910), How we think, New York, D. C. Heath (reprint)

11. Fendt, J. (2002i), Learnings about Learning in M\&A Transitions: A Qualitative Exploratory Study in Preparation of A Dissertation on The Influence of Management Andragogy on Executives' Ability to Successfully Manage Transition in M\&A Environments, International Journal of Business \& Economics, Fall 2002, Vol.2, No.1

12. Fendt, J. (2002ii), Why German Entrepreneurial Activity is still lagging behind the USA: Looking at Social Legitimacy, Equity Financing and Managerial Competence, in: Berndt, R. (Ed.), Management Konzepte für die New Economy, Vol. 9, Springer 2002

13. Fendt, J., Baumann M. (2003), The Impact of the Enron Debacle on Executives' Perception of Leadership Effectiveness, to appear in: Berndt, R. (Ed.), Leadership in Difficult Times, Vol. 10, Springer 2003

14. Financial Times Deutschland (2001), Die Top 500 Europas 
15. Gomez/Hahn/Müller-Stewens/Wunderer (Hrsg.) (1994) Unternehmerischer Wandel: Konzepte zur organisatorischen Erneuerung, Gabler

16. Grubb, T., Lamb, R. (2001) Capitalize on Merger Chaos: Six Ways to profit from your Competitors' Consolidation and your Own, Simon\&Schuster Free Press 2001

17. Harbir, S., Zollo, M. (1999), Post-acquisition Strategies, Integration Capability and the Economic Performance of Corporate Acquisition, http://www-management.wharton.upenn.edu/singhh/hightech/files/AcquisitionPerformance.pdf

18. Haspeslagh, P.C., Jemison, D.B. (1991), Managing Acquisitions, New York Free Press 1991

19. Krishnan, H.A., Miller, A., Judge, W.Q. (1997), Diversification and Top Management Team Complementarity: is Performance Improved by merging Similar or Dissimilar Teams? Strategic Management Journal 18 361-374

20. Jansen, S.A. (2001), Pre- und Post Merger Integration bei grenzüberschreitenden Zusammenschlüssen, in: ders. / Picot, Gerhard / Schiereck, Dirk (Hrsg.) (2001): Internationales Fusionsmanagement Erfolgsfaktoren grenzüberschreitender Zusammenschlüsse, Stuttgart: Schäffer-Poeschel, $M \& A R E V I E W$, pp. 3 - 342001

21. Jemison, D. B., Sitkin. S.B. (1986), Corporate Acquisitions: a Process Perspective. Academy of Management Review, 11, 145-162 1986

22. Knowles, Malcolm S. (1980), The Modern Practice of Adult Education: Andragogy vs. Pedagogy, Rev.ed. New York, Association Press

23. Keite, Lothar (2001), Fusionen: einen Schritt vor, zwei zurück, Absatzwirtschaft, 9/2001:58-64

24. Knowles, Malcolm S., Elwood F. Holton III, and Richard A. Swanson (1998): The Adult Learner, Houston, Gulf Publishing

25. Krusche, B. (2000), M\&A: Perspektiven der Beratungsarbeit, GWS-Forum Wiesbaden 2000

26. Lawler, Patricia A. (1991), The Keys to Adult Learning: Theory and Practical Strategies, Philadelphia, Research for Better Schools

27. Lewin. K. (1951), Field Theory in Social Sciences, New York, Harper and Row

28. Mailick, S. and Stumpf, S (1998), Learning Theory in the Practice of Management development. Evolution and Applications, London, Quorum Books

29. Merriam, S. B.,Caffarella R. S. (1999) Learning in Adulthood: A Comprehensive Guide, San Francisco, Jossey Bass

30. Mezirow, Jack (1991), Transformative Dimensions of Adult Learning, San Francisco, Jossey Bass

31. OECD Science, Technology and Industry Scoreboard 2001 (2002)-Towards a knowledge-based economy, http://www1.oecd.org/publications/e-book/92-2001-04-1-2987/C.3.2.htm 2002

32. Ohmae, K. (1990), The Borderless World: Power and Strategy in the Interlinked Economy, HarperBusiness p. $114-136$

33. Pümpin, C., Kobi J. M., Wüthrich, H. A. (1985) Unternehmenskultur: Basis strategischer Profilierung erfolgreicher Unternehmungen, Schweizerische Volksbank Nr. 85, 1985

34. Roll, R. (1986), The Hybris Hypothesis of Corporate Takeovers, Journal of Business 59 197-216, 1986

35. Romig, F. (1966), Theorie der wirtschaftlichen Zusammenarbeit, Berlin

36. Rouiller, J., Goldstein, I. (1993), The relationship between organizational transfer climate and positive transfer of training. Human Resources Development Quarterly, 4, 377-390.

37. Sahl, Robert J.(1998), Remedies For Curing The Post-Merger Blues - Getting employees to accept their new situation after a merger can be a difficult task, WMS Quarterly of Webber, Meng, Sahl and Co.

38. Schmidt, S. (1999) Wenn Unternehmen fusionieren... M\&A - die unternehmenskulturelle Dimension, Softlab GmbH White Paper 1999

39. Schuler, R. S.Jackson, S.E. (2001), HR Issues and Activities in Mergers and Acquisitions, European Management Journal (2001)

40. Schuler, R. S., Jackson, S.E., Fendt, J. (2003) HR Leader, Staff and Department, to appear in: Berndt, R. (Ed.), Leadership in Difficult Times, Vol. 10, Springer 2003

41. Senge, P. et al (1999), The Challenges of Profound Change, in: Arthur D. Little (Ed.), Prism 2/1999

42. Stähli, A. (1988), Management Andragogik I, Zürich, 1988

43. Stähli, A. (1992), Europäische Lösung: Genetisch wachsende Fallstudie, Management Andragogik II, London 1992 
44. Stähli, A. (1999), Management-Andragogik in der Business School 2000, in: Berndt. R. (Ed.), Management Strategien 2000, Springer Berlin 1999

45. Stähli, A. (2000). Innovationsmanagement und die Business School 2000, in: Berndt, R. (Ed.) Innovatives Management, Springer Berlin, 2000

46. Steinöcker, R. (1998) Mergers \& Acquisitions: Strategische Planung von Firmenübernahmen

47. Ulrich, H. (1987), Ausbildung von Führungskräften zum ganzheitlichen Denken und Handeln, in: Eschenbach, R. Manager für morgen, Vienna 1987

48. Valentine, D. A. (1999), Global Mergers: Trade Issues and Alliances in the New Millenium, 10th Annual OWIT Trade Conference, Georgetown University Washington

49. Walker, R. (2002), Post-Enron, spirituality gains, in: The Christian Science Monitor, April 2002 http://www.csmonitor.com/2002/0429/p20s03-wmwo.html

50. Watson Wyatt (2000), European results of the global M\&A Survey, http://www.watsonwyatt.com/homepage/eu/res/surveys/mergersand acquisitions/0600/index.htm King of Prussia, Pennsylvania.

Notes 